\title{
¿QUÉ OCURRE CON LA EMPLEABILIDAD? REFLEXIONES CRÍTICAS SOBRE SU ORIENTACIÓN Y DESAFÍOS EN TIEMPOS DE CRISIS
}

\author{
What about employability? Critical reflections on employability approach \\ and challenges in times of crisis
}

\author{
Elsa Santamaría López*, Xavier Orteu Guiu
}

Universitat Oberta de Catalunya, España

\section{RESUMEN}

Este artículo revisa las limitaciones que las políticas activas de empleo, bajo la lógica de la empleabilidad, tienen en las posibilidades de inclusión en el mercado de trabajo. Se observa que la lógica de la empleabilidad, integrada en el imaginario neoliberal, lejos de tener unos resultados claros en la mejora de la participación laboral, contribuye a las desigualdades y a las situaciones de desprotección y de precariedad laboral contemporáneas. Por lo tanto, se propone la necesidad de encontrar otros enfoques de la empleabilidad que sitúen al trabajo como una forma de participación social y no únicamente como una modalidad de provisión de ingresos. Se concluye que para que la empleabilidad no se limite sólo a una cuestión de mejoría técnica en el acceso a un empleo, necesitaría ser encauzada como una herramienta colectiva de recuperación del sentido de pertenencia y de utilidad social.

Palabras clave: empleabilidad, precariedad, desigualdades, políticas activas de empleo

\section{ABSTRACT}

This article reviews the limitations that active employment policies, under the logic of employability, have on the possibilities of inclusion in the labour market. It is observed that the logic of employability, with a neoliberal approach, far from having clear results in improving labour participation, contributes to inequalities and to contemporary situations of lack of protection and labour precariousness. Therefore, it is proposed that other approaches to employability be found that situate work as a form of social participation and not only as a modality of income provision. The conclusion is that if employability is not to be limited to a question of technical improvement in access to employment, it would need to be channelled as a collective tool for recovering a sense of belonging and social usefulness.

Keywords: employability, precariousness, inequalities, active employment policies.

\footnotetext{
* Correspondencia a: Elsa Santamaría López. Universitat Oberta de Catalunya (UOC), Rambla del Poblenou, 156, 08018 Barcelona (España) - esantamaria|@uoc.edu - https://orcid.org/0000-0001-9000-7879

Cómo citar: Santamaría López, Elsa; Orteu Guiu, Xavier. (2020). "¿Qué ocurre con la empleabilidad? Reflexiones críticas sobre su orientación y desafíos en tiempos de crisis"; Lan Harremanak, 43, 21-40. (https://doi.org/10.1387/lan-harremanak.21657).

Recibido: 19 abril, 2020; aceptado: 09 junio, 2020.

ISSN 1575-7048 - eISSN 2444-5819 / (c) 2020 UPV/EHU
} 


\section{Introducción}

El avance del capitalismo ha seguido un ritmo acelerado desde los años 70 y 80 del siglo pasado, adaptando los empleos a un tipo de producción más inestable y flexible que se desenvuelve en una escala de dimensiones globales. Por aquellos años también se produce un giro neoliberal predominante en las políticas económicas y en las políticas de gestión del empleo, mediante las cuales el trabajo queda cada vez más desregulado y subordinado a los vaivenes de los mercados. Como consecuencia de la flexibilidad en los procesos productivos y la desregulación de las prácticas laborales, ha aumentado la precariedad laboral, tanto en el trabajo asalariado como en las nuevas formas de empleo. Pero esta precariedad se ha venido manifestando no sólo en las formas de empleo (más temporal, parcial y externalizado) sino también en procesos como el marcado individualismo, que responsabiliza a los sujetos de su situación en el mercado laboral, o una concepción del tiempo, acelerado y cortoplacista, en el que se produce una intensificación del trabajo con continuas exigencias laborales y profesionales. Se trata de procesos marcados por una racionalidad neoliberal, que somete la relación con el trabajo a los principios de competencia y rentabilidad de los resultados, y que no sólo se quedan en el ámbito laboral, sino que se extienden a otros ámbitos de la vida social, imponiendo una determinada forma de organizar el mundo y la vida (Laval y Dardot, 2013).

Así como las transformaciones del mundo del trabajo no pueden ser entendidas sin tener en cuenta los cambios acontecidos aquellos años, más adelante, en concreto desde el periodo del cambio de siglo, se vienen sucediendo una serie de procesos ligados a la digitalización y la automatización que están generando todavía más dudas y distorsiones en el mundo del trabajo en particular, y en el sistema económico en general. Algunas interpretaciones de estos cambios se han hecho bajo la idea de transición hacia una «economía informacional» (Castells, 1996), un "capitalismo digital» (Schiller, 2000) o de un "capitalismo cognitivo» (Moulier Boutang et al., 2004), entre otros.

En este escenario transicional, son recurrentes los debates acerca del futuro del empleo en los que se pronostica que la tecnología hará desaparecer gran parte de los empleos existentes. Realmente desconocemos las dimensiones que puede adquirir este posible «desempleo tecnológico» como tampoco podemos saber, si los nuevos empleos que puedan crearse serán suficientes para contrarrestar los que desaparezcan. Lo que sí que está más claro es que procesos como la automatización y la digitalización seguirán avanzando teniendo un papel principal, como ya puede verse, en la creación de nuevos modelos de negocio (Startups, economías de plataforma, etc.) y también en el desarrollo de diferentes modalidades de trabajo (por objetivos, por proyectos, microtareas, bajo demanda, etc.). Los efectos de lo digital se están manifestando transformando dónde, cuándo, cómo y con qué capacidades y habilidades trabajamos. También lo digital está 
entrando en otras dimensiones de las relaciones laborales, como son: los procesos selectivos, la búsqueda de trabajo, el desarrollo profesional, entre otros.

Los análisis empíricos que hay sobre los procesos de transformación digital, ponen de relieve que no se están desarrollando de forma homogénea, sino que registran variaciones significativas entre las diferentes zonas geográficas, sectores productivos y tipos de empresa. A esto se suma, además, el hecho que las oportunidades y las precariedades que genera este fenómeno (modalidades de empleos al margen de los contratos laborales, explotación, discriminación, etc.) se reparten de forma desigual sobre los distintos grupos de población, en base a variables como el género, edad, origen, nivel de cualificación o de renta (Eurofound e International Labour Office, 2019).

A todo esto, nos encontramos que para poder tener un diagnóstico apropiado del mundo del trabajo tenemos que atender a las consecuencias de sucesivas crisis económicas, como la crisis financiera del año 2008 que fue devastadora para el empleo, a partir de la cual se vivieron unas elevadísimas tasas de desempleo fundamentalmente en los países del sur de Europa y la más reciente crisis sanitaria del año 2020, con la declaración de pandemia global por el virus COVID-19, cuyo impacto económico se está gestando todavía y cuyas consecuencias son difíciles aún de predecir. Precisamente, en la redacción de este artículo, nos encontramos inmersos en un "estado de alarma» y con medidas de confinamiento, en plena crisis sanitaria de la que poco sabemos aún cómo va a ir avanzando, pero cuyos efectos sobre el empleo presagian ser «devastadores» (OIT, 2020). Las medidas tomadas para frenar la expansión del virus han supuesto la frenada en seco de la actividad de sectores económicos enteros, con los consiguientes despidos y con la extinción y no renovación de los contratos temporales. Exactamente los focos de precariedad del mercado de trabajo español, en que el número de personas desempleadas es alto y se depende de una excesiva temporalidad laboral. Los despidos se han tratado de paliar en cierta medida por la extensión de los Expedientes de Regulación Temporal de Empleo (ERTES) con condiciones excepcionales, y se han tenido que establecer prestaciones y subsidios extraordinarios para determinados colectivos. Aquellos sectores que han podido mantener la actividad, lo han hecho ralentizando producciones, gestiones y servicios y sobre todo gracias a la extensión del teletrabajo, que ha adquirido una generalización imposible de pensar antes de esta pandemia.

Desde esta fase inicial de crisis y sin tener claro cuál será su rumbo, podemos vislumbrar que vendrán tiempos de incertidumbre aún mayores para el empleo y que serán más necesarias que nunca, políticas que antepongan el bien común a los beneficios económicos, garantizando las condiciones de vida, así como la protección social fundamental para las personas que más lo necesitan.

En todo caso, es importante señalar es que los debates sobre el futuro del empleo quedan incompletos si no se tiene en cuenta también el futuro del tra- 
bajo. Y esta diferencia entre empleo y trabajo deviene fundamental. Si el trabajo es el nombre que toma actividad humana destinada a generar valor social, el empleo sólo sería la modalidad actual que ha tomado una parte de esta actividad. Una modalidad condicionada a un salario que ha generado una serie de mecanismos de participación social que ahora están en transformación. Justamente, si algo ha puesto de relieve la crisis actual a diferencia de la del 2008, es la necesidad de los cuidados, en los hogares, pero también en hospitales, residencias, centros de día, etc. y de la comunidad, de toda una serie de trabajos no remunerados económicamente pero imprescindibles para nuestra supervivencia y para nuestra integración. El trabajo de los cuidados, feminizado y relegado siempre a la invisibilidad y la falta de reconocimiento, se convierte en un elemento necesariamente a replantear, ya que no podemos seguir obviando, como viene desde hace tiempo denunciando la economía feminista, el papel clave que tiene en la organización de nuestras vidas (Carrasco, Borderias, Torns, 2011; Pérez Orozco, 2014; Méda, 2019).

Por lo tanto, nos tenemos que situar en un escenario complejo en el que una serie de procesos, que trascienden lo laboral, van a condicionar enormemente no sólo el empleo sino también el trabajo. Estos cambios se van a sumar a otras transiciones en marcha como son: la demográfica, en concreto con el envejecimiento de las poblaciones occidentales, y la ecológica, con el agotamiento de los recursos energéticos tradicionales y con el cambio climático.

La previsible recesión económica y los procesos de cambio señalados acentuarán los procesos de desigualdad y también los procesos de exclusión laboral $\mathrm{y}$, a los colectivos tradicionalmente situados en los márgenes del mercado de trabajo o expulsados del mismo, habrá que sumar nuevos colectivos afectados por factores de vulnerabilidad y/o en riesgo de exclusión sociolaboral en el propio mercado de trabajo. Claro ejemplo de ello, son ya el precariado, los trabajadores y trabajadoras pobres o los autónomos y autónomas sin derechos, entre otros.

En este escenario de transformaciones laborales, el objetivo de este artículo es revisar el papel de la empleabilidad como modelo de intervención en las políticas activas de empleo en el contexto español. Para ello, hemos transitado una serie de lugares por los que las ciencias sociales preocupadas por el trabajo y, más en concreto, por el empleo ya han pasado, como es el valor social del trabajo, su potencial integrador y los cambios que ha experimentado en los últimos años. Asimismo, hemos llevado a cabo una revisión de los estudios disponibles sobre la empleabilidad. Encontramos que la mayoría de ellos están centrados en definir el concepto o constructo de empleabilidad e identificar las múltiples dimensiones que lo conforman, pero sobre todo, están preocupados por medir la empleabilidad o encontrar la fórmula para ello. Sin embargo, lejos de aquellos análisis que toman de una forma acrítica la empleabilidad, nuestro interés se ha centrado en sintetizar las aportaciones de los estudios que tratan de 
comprender e identificar las implicaciones sociales de la lógica de empleabilidad (Serrano, 2000, 2009; Santos-Ortega, 2008; Chertkovskaya et al., 2013, Moruno, 2015). Es precisamente a partir de estos análisis que desvelan la mercantilización del trabajo y el enfoque neoliberal de la empleabilidad, que trabajamos con la hipótesis de que la empleabilidad bajo esta racionalidad moldea una parte fundamental de los factores de exclusión social, con características y dinámicas similares a las que ya conocíamos hasta ahora, pero con nuevos matices y sobre todo más móviles y fluidas que antes. Por ello nuestra propuesta pasa por plantear una necesaria reformulación del enfoque de la empleabilidad en la relación con el trabajo y en su papel en las trayectorias laborales contemporáneas. En este aspecto nos apoyamos en los aprendizajes desarrollados en el marco del trabajo diario de una cooperativa de inserción sociolaboral catalana: Inserccop y en los resultados de varios proyectos de reflexión y evaluación en los que ha colaborado la entidad y los autores. Los resultados se reflejan en el Informe «Mejora de la empleabilidad desde la acción comunitaria» (Orteu, 2016) en el que se reflexiona sobre las posibilidades y límites de la empleabilidad a partir del análisis de un programa destinado a favorecer la inclusión social y laboral a través del aprendizaje digital, la vinculación de las personas en su entorno y la orientación sociolaboral. También en el Informe «Entre el empleo y el trabajo» (ECAS, 2019) en el que se realiza un análisis de diferentes experiencias desarrolladas por varias entidades sociales catalanas y donde se plantea la inserción laboral desde la perspectiva del derecho a la inclusión. Este enfoque permite restituir el valor social del trabajo y facilitar procesos a las personas desempleadas por la vía de su utilidad social y no solo mercantil.

El recorrido de este artículo comienza situando el valor del trabajo como elemento de construcción del vínculo social para continuar analizando la empleabilidad y las consecuencias de su enfoque neoliberal. Pero la empleabilidad puede orientarse de otra forma, y esta es la propuesta del artículo. De modo que, en los apartados finales se plantea una mirada que, sin desconocer ciertas limitaciones, aspire a repensar la empleabilidad en las nuevas condiciones económicas, tecnológicas y sociales, y busque articular lo que durante demasiado tiempo ha estado desarticulado: una propuesta de modelo de trabajo que incorpore tanto el empleo remunerado como el trabajo en el marco del bien común.

\section{La desaparición del trabajo como orientación al otro}

Para situar la problemática de la legitimidad de la empleabilidad en la actualidad, hay que tener en cuenta que la dimensión social del trabajo y, por tanto, los sistemas que regulan su acceso y participación son un producto histórico (Castel, 2006). No siempre se sabe separar las funciones sociales del trabajo del contexto en que se han dado y, por tanto, no siempre se presta atención 
al entender que los límites entre trabajo y no trabajo no son naturales, sino que dependen de las condiciones sociales (de la Garza Toledo, 2009). Si existe el vínculo social en el marco de la actividad laboral es por qué se han buscado las condiciones para hacerlo posible. Nos interesa pues explorar las condiciones de posibilidad en la construcción del sujeto social teniendo en cuenta los cambios actuales. Es decir, comprender en qué medida el trabajo puede seguir haciendo de puente articulador del sujeto con la sociedad en que vive. Por tanto, la pregunta es sobre qué es lo que nos permite hacer vínculo social (Orteu, 2012).

En la actual orientación de la empleabilidad desaparece esta cuestión que tiene una larga trayectoria en el debate sobre el valor social del trabajo y sus regulaciones necesarias. Haciendo un breve de repaso histórico, podemos decir que para Durkheim, la división social del trabajo no tiene que ver con el aumento de la productividad - como plantearía Smith - sino con el ejercicio de la solidaridad social entendido como sentido de utilidad social (García Calavia, 2013). La lógica del don, de aquello que se da sin pedir nada a cambio (que tan brillantemente fue estudiado por Marcel Mauss), sería la base de las afirmaciones de Durkheim (Linhart, 2013). Podríamos decir que Durkheim entiende que el don es un efecto de la socialización de la interdependencia social, de la necesidad de existir en el campo del otro. En el caso del trabajo, este don se traduce en una división el trabajo donde cada uno ocupa un lugar con valor para el resto de la comunidad. Es por ello posible la construcción del vínculo social a través del trabajo. Durkheim pone el énfasis en la importancia de la división del trabajo por lo que supone de integración social de las personas. Porque lo sitúa en una relación con lo social. Porque les permite la adquisición de un sentimiento de utilidad al conjunto de la sociedad y porque refuerza la complementariedad de los individuos obligándoles a cooperar.

El trabajo, además de convertirse en el medio básico de obtención de ingresos, también ha supuesto la ocupación principal durante el tiempo socializado. Quien no trabaja sufre, pero no sólo por no disponer de ingresos, sino por una falta de sentido de utilidad social (Castel, 2006). Según esta idea, la dirección actual del empleo tiende a deshacer esta dimensión colectiva. El marco laboral se está convirtiendo actualmente en un espacio de fuerte individualización y las nuevas formas de organización introducen aquí una diferencia fundamental: apuntan a una movilización individual, no desde el valor común. Es una orientación al individuo que hace de barrera a los valores colectivos vinculados con el mundo del trabajo.

El mundo del trabajo se ha ido transformando y se han desarrollado nuevas formas de organización que apuntan a dos aspectos: por un lado a una orientación narcisista, es decir, una orientación donde se pone de relieve la ausencia del otro social; y por otra parte, a una orientación al mercado. De este modo, se exige una interiorización de los objetivos económicos y mercan- 
tiles por parte de las personas trabajadoras. Si unimos los dos aspectos es fácil deducir las consecuencias sobre el cambio en la función socializadora del trabajo. Se reduce la distancia en la que el trabajo pueda funcionar como una orientación al otro.

La dinámica del mercado laboral tiende a reducir este espacio donde se gesta el vínculo social y se construyen las identificaciones de las personas trabajadoras con la comunidad. En realidad, esta distancia es la que permite la inscripción sociolaboral de cada persona en la comunidad. Esto es importante porque esta inscripción habla de la posibilidad de articulación entre los propios ideales y las normas que regulan lo social. Para Laval y Dardot (2013) la nueva configuración laboral deja de ofrecer un marco estable en el que poder construir un proyecto personal y esto tiene efectos en la vida privada, la organización familiar y la representación de uno mismo. El debilitamiento de esta inscripción provoca que los roles asociados también se estén diluyendo. La disolución de las fronteras personales, laborales y sociales hace que surjan nuevas reglas sociales. Todo ello genera un malestar por la pérdida de sentido de lo que ordenaba. La desregulación de la relación con lo laboral hace que los recorridos sean diversos, las intermitencias constantes y la capacidad de combinar los diferentes tiempos y experiencias se multipliquen hasta un punto desorientador.

El problema de este malestar social en relación al empleo es que tiene una pata en el salario y otra en el reconocimiento. Y no es que el malestar actual sea superior al malestar de otras épocas en las que también ha habido altos índices de desempleo e incluso precariedad laboral. El problema es que actualmente resulta más difícil de canalizarlo ya que el empleo ha perdido la capacidad de atracción y organización colectiva que permitía orientar los ideales personales y sociales (García Calavia, 2013). Es por este motivo que podemos afirmar que estamos inmersos en un cambio en el modelo de convivencia social en el que el empleo era su columna vertebral. Actualmente las personas excluidas del mercado laboral representan 1 de cada 4 personas en edad activa en Espańa (FOESSA, 2019). Estas personas presentan diferentes tipos de dificultades relacionadas con inserción laboral y hay que saber que la ausencia de capacidades productivas sólo es una de ellas. La otra y no menos importante, es que se difumina el marco social que le permitía una relación simbólica con el empleo. La posibilidad de pertenecer a la sociedad a través de su inclusión laboral queda obsoleta. Ya no le sirve ni para disponer de unos ingresos seguros, ni para sentirse socialmente útil. En definitiva, para algunas personas, cada vez resulta más difícil ubicarse en una sociedad que ha transformado la centralidad del trabajo sin preocuparse de las nuevas exclusiones que genera.

En el VIII Informe FOESSA, que alerta de cómo la exclusión social se enquista en la estructura social, se defiende la tesis de que vivimos en una sociedad desvinculada, en la que cada vez es más difícil hacernos cargo de los que se que- 
dan atrás y que, por ello, es necesario que nos re-vinculemos, un objetivo en el que la construcción de comunidad tendrá un papel esencial (FOESSA, 2019).

Standing (2013) popularizó una forma de denominar a las personas que se encuentran en esta situación: el precariado. Habitualmente se piensa que el único aspecto que define al precariado tiene que ver con las condiciones laborales, pero el análisis que hace el autor desmiente este punto y añade la falta de apoyo comunitario y un proceso de desvanecimiento de la identidad laboral como otros aspectos clave a tener en cuenta. Justamente estas cuestiones se pudieron observar en el análisis del Programa Omnia (Orteu, 2016). La precariedad laboral es un reflejo de la precariedad de los lazos sociales, pero también lo podríamos formular al revés: la fragilidad social conlleva fragilidades en la empleabilidad. En esta línea, Autès (2005) apunta que la pérdida de lazo social no es la pérdida de los vínculos sociales, sino del lazo identitario. Uno ya no sabe quién es, siente que ya no tiene un lugar en la sociedad.

\section{Implicaciones del enfoque actual de la empleabilidad}

La preocupación por la empleabilidad ha centrado los intereses de las instancias políticas desde los años 90, siendo uno de los pilares de las políticas activas de empleo que se fomentan desde la Estrategia Europea de Empleo (EEE) (Lefresne, 1999, Gazier, 2001; Serrano, 2000). Pero a día de hoy, los discursos y prácticas sobre la empleabilidad se han extendido y han traspasado las fronteras del ámbito político, calando en el mundo empresarial, en el mundo educativo y especialmente, en la educación superior (Yorke, 2006; Boden y Nedeva, 201; Tomlinson y Holmes, 2017), con el afianzamiento del desarrollo competencial.

Desde el enfoque competencial que prima a la hora de abordar la empleabilidad, ésta es entendida como el desarrollo de competencias necesarias para insertarse en el mercado de trabajo y permanecer en él a lo largo del tiempo, o poder volver, en caso de que se abandone temporalmente. Este es el enfoque que sigue primando y que se ha revitalizado en los actuales debates acerca del futuro incierto del trabajo. La Real Academia de la Lengua Española tiene la siguiente definición acordada: «Conjunto de aptitudes y actitudes que permiten a una persona conseguir y conservar un empleo». En el ámbito académico, la empleabilidad ha sido abordada desde diferentes enfoques y se ha tratado de llegar a una definición más o menos consensuada (McQuaid y Lindsay, 2005; Guilbert et al., 2016). Y aunque se comparte que se trata de un concepto difuso, carente de claridad y especificidad de significado, han primado los estudios que tratan de medir y cuantificar el fenómeno, abordando la empleabilidad como un constructo operativo. Sin embargo, lo que nos interesa resaltar de este concepto, no es tanto su definición y los diferentes abordajes que puede tener, sino 
más bien las implicaciones sociales de la forma en la que se maneja en la actualidad, es decir, las implicaciones del enfoque que prima en la empleabilidad. Porque la empleabilidad, tal y como es utilizada generalmente en el debate público, ha pasado de ser una noción prácticamente desconocida, incluso un palabro algo forzado, a conseguir una connotación social muy positiva. En estos tiempos de incertidumbre y precariedad laboral buscar, fomentar o impulsar la empleabilidad ha ido adquiriendo un papel protagonista en las políticas de empleo con un efecto normativo sobre todo para ciertos colectivos, los que tienen más dificultades de acceso al mercado de trabajo, pero, es más, la responsabilidad individual de "hacerse empleable» ha devenido en imperativo para cualquiera en edad de trabajar.

No podemos obviar que se trata de un enfoque neoliberal que hace hincapié en la responsabilidad individual de los éxitos y los fracasos en el mercado de trabajo y que prioriza una idea de capital humano corporeizado en los individuos (Muñoz y Santos, 2017). Al poner el foco en la empleabilidad, las dificultades de acceso al empleo se visualizan como carencias personales de distinto tipo (educativas, de capacitación, de motivación, de adaptabilidad). Así mismo, como está estrechamente vinculada al paradigma de la activación (Barbier, 2001 y 2006, Serrano, 2009), la empleabilidad ejerce como un dispositivo de autoresponsabilización de uno mismo o una misma ante las situaciones de desempleo, haciendo creer a las personas que es debido a su insuficiente empleabilidad la razón fundamental por la que no pueden conseguir un trabajo.

La agenda de la empleabilidad se ha ido consolidando en los últimos años, puede ser que en cierta forma impulsada por el deterioro de las condiciones del mercado laboral y se ha recurrido a su fomento, también en los momentos de crisis económica (Chertkovskaya et al., 2013; Serrano y Martín, 2017). Nada más actual para la situación que estamos viviendo. Este enfoque dominante sobre la empleabilidad, de carácter neoliberal, impregna las lógicas de intervención en materia de empleo con unas implicaciones claras sobre los marcos de sentido del trabajo y de los sujetos trabajadores.

Desde una lectura crítica, algunas de las implicaciones de este enfoque neoliberal sobre la empleabilidad podrían quedar resumidas en las siguientes cuatro afirmaciones, que apelan precisamente a los fundamentos sobre los que se sustenta: la empleabilidad sigue una lógica individualista; no mejora ni la calidad ni la cantidad del empleo; sigue una lógica competitiva que perpetúa las desigualdades; y solo pone el foco en el mercado laboral y no en otros trabajos socialmente útiles.

- La empleabilidad sigue una lógica individualista que responsabiliza a las personas de su situación en el mercado laboral. Se trata de una de las principales críticas que realiza a la empleabilidad. Según Alonso «La acti- 
vación, la empleabilidad y el aprendizaje son los lugares discursivos a los que acude la actual retórica de la individualización de las responsabilidades y el autocontrol de la carrera laboral» (2007: 243)

La empleabilidad pone el énfasis en la responsabilidad individual de formarse para el empleo y de emplearse, es decir de "hacerse empleable», como si se tratase de un "empresario de sí mismo" (Foucault, 2007). La génesis de la problemática laboral, sea del tipo que sea, se considera una cuestión básicamente individual, producida por desajustes de los sujetos en el mercado laboral; desajustes que deben resolverse a través de su capital humano, es decir, de las estrategias desplegadas por sí mismos en el marco de la competencia por la empleabilidad.

La empleabilidad es persuasiva, viene a significar que cada uno debe «ocuparse en el esfuerzo de la ocuparse», es decir, que al deseo de trabajar, hay que sumarle la motivación para buscar empleo, la capacidad de saber buscarlo, la disposición para adquirir la información necesaria, la capacidad de esfuerzo para mejorar las competencias como trabajador y además tener una actitud positiva, ánimo, autodisciplina, ganas de superación, confianza en uno mismo, etc. Como afirma Alaluf «los diversos discursos sobre la movilización de los trabajadores según competencias, lejos de descubrir una pretendida afirmación de un vinculo natural entre trabajador y su trabajo, individualizan y naturalizan los resultados clasificatorios de las relaciones salariales» (2003: 93).

El (re)conocimiento de que cada uno debe abrirse camino en un escenario laboral cambiante, marcado por una incertidumbre prácticamente inevitable, trae consigo procesos que han generado la necesidad de establecer mecanismos de confianza, como diría Giddens, mediante los que se legitima la existencia un conocimiento experto que intenta, aunque no siempre lo consigue, resolver los peligros que nos amenazan.

Como ya se ha señalado, la evolución en los modelos de intervención para la inserción laboral y para la empleabilidad implican un cambio en el discurso en el que se basan las políticas sociolaborales, que dejan de apoyarse en el derecho ciudadano a unas determinadas prestaciones sociales para hacerlo sobre la responsabilización individual y la autonomía personal frente al riesgo de dependencia y cronificación (Wacquant, 2011). En definitiva, la individualización y la despolitización en la forma de tratar la inserción laboral está alimentando un modo de subjetivación que casa perfectamente con la manera como el capitalismo avanzado afronta sus retos y sus crisis productivas (Crespo, Prieto, y Serrano, 2009). A ello se suma la debilidad de unos Estados de Bienestar que ante las dificultades de generar empleo, tratan de asegurar la empleabilidad y la activación de los individuos.

- La mejora de la empleabilidad no aumenta la cantidad de empleo, ni mejora la calidad del mismo. La mejora de la empleabilidad no implica 
un crecimiento en las ofertas de empleo, ni mejora la calidad de los empleos que se ofrecen. En este sentido, las críticas más habituales al tratamiento de la empleabilidad se centran en advertir que los esfuerzos realizados por y en las personas dejan intacta la forma de proceder de los mercados laborales. Ante la escasez de empleo y ante la generación de empleo precario, el trabajo sobre la empleabilidad supondrá avanzar alguna posición en las listas del paro y en el mejor de los casos, conseguir un empleo, lo más seguro, de baja calidad, porque «la empleabilidad también es aceptar malas condiciones de trabajo, bajos salarios y erosión de derechos» (Moruno, 2015: 140). De mientras, los factores de exclusión y de precarización del mercado de trabajo, quedan sin ser abordados.

$\mathrm{Y}$ es que como venimos comprobando, el discurso sobre la empleabilidad enfatiza el fomento de la mejora de las condiciones individuales en el mercado de trabajo, pero dejando intactas las condiciones de ese mercado de trabajo. El auge del emprendimiento en los últimos tiempos está inmerso en esta misma lógica lo que genera posiciones claramente paradójicas a quienes se ven en la necesidad de emprender en las actuales condiciones de precarización laboral (Serrano y Martín, 2017; Santamaría y Carbajo, 2019).

- La empleabilidad sigue una lógica competitiva que perpetúa desigualdades estructurales el mercado de trabajo. Algunos estudios que han abordado la empleabilidad y han puesto sobre la mesa la necesidad de considerar que la empleabilidad no tiene más remedio que ser tratada como una condición inestable y relativa, que no depende de su valor absoluto sino de cómo se posicionan otros en la competencia por un puesto de trabajo (Brown et al., 2003 y 2011).

Peck y Theodore (2000) ya pusieron de manifiesto que el enfoque habitual que manejan las instituciones sobre la empleabilidad tiende a favorecer que sean las personas "más empleables» las que consigan los empleos, mientras que los casos más difíciles, más desaventajados o marginalizados, tienden a permanecer como están. De esta forma, se estarían perpetuando los patrones vigentes de desigualdad en el mercado laboral, y priorizando la inserción laboral de aquellas personas más cercanas al mercado de trabajo.

Poner el énfasis en los aspectos individuales y en el gobierno de la subjetividad (Rose, 1999), interpretando la cuestión del desempleo y la precariedad únicamente en términos de empleabilidad individual, y no, por ejemplo, en términos de desigualdades estructurales acentúa el enquistamiento de la desigualdad y ahonda en la fragmentación tan acusada que sufre el mercado de trabajo español.

Desde ese punto de vista, autores como Peck y Theodore (2000) apuestan por un enfoque redistributivo de los programas de activación, que se 
centre en las personas menos empleables y limite las desigualdades en el seno del mercado laboral, mediante medidas anti-discriminación, educación y formación de calidad, prestaciones económicas adecuadas y la extensión de los derechos laborales.

- La empleabilidad pone el foco exclusivamente en la consecución de un trabajo en el mercado laboral, cuando hay otros trabajos socialmente útiles imprescindibles para la supervivencia de la familia pero también de nuestra vida social. Aunque consideremos la inserción laboral como un mecanismo fundamental para la inclusión social, está ampliamente demostrado que hay procesos de exclusión en los que la consecución de un empleo no protege frente a la pobreza y la marginación. La cuestión es que la exclusión social es un fenómeno multicausal y que no puede ser pensada y menos superada únicamente desde una de las posibles dimensiones que entran en juego en los procesos de exclusión (Subirats et al., 2005, Laparra y Pérez-Eransus, 2008).

El hecho de tener que atender a la multidimensionalidad de la exclusión y de la inclusión social pone sobre la mesa varias cuestiones que van concatenadas y que afectan a la lógica actual de la empleabilidad. En primer lugar, la necesidad de no sobrevalorar los efectos o consecuencias posibles de la inserción en el mercado laboral y en segundo lugar, insistir en la idea de que ese mercado sólo se tiene en cuenta el empleo y no otros trabajos de gran utilidad social. En esta línea, son fundamentales los aportes desde la economía feminista que evitan equiparar de forma reduccionista el trabajo con el empleo remunerado, porque hacerlo no ha llevado más que a minusvalorar otros tipos de actividades y trabajos que suponen una gran aportación a la sociedad.

En este sentido, sería conveniente abordar la empleabilidad partiendo de una concepción amplia de trabajo, que no se limite al empleo remunerado y reconozca otras aportaciones posibles, principalmente, aunque no únicamente, del ámbito de los cuidados y de las economías transformadoras. De la Cal y De la Fuente dibujan con claridad el escenario que abre un enfoque en el que la intervención en materia laboral tuviera en cuenta una visión amplia del trabajo:

Se debería definir todo el trabajo que es útil y necesario en nuestras sociedades, dentro del cual se encuentran el trabajo doméstico, el de cuidados, el trabajo voluntario, que hoy día no son valorados ni reconocidos. Asimismo, se deberían considerar también como equivalentes al trabajo otras actividades como las formativas y educativas, considerando su contribución al desarrollo económico y social futuros. Este sería un importante paso para que las personas que llevan a cabo todo este trabajo tengan roles sociales alternativos a los que proporciona el empleo, pero igualmente reconocidos, legitimados y valorados por la sociedad. (2010: 83) 


\section{4. ¿Cómo podría jugar la empleabilidad?}

La empleabilidad se encuentra en la paradoja: se trata de un discurso que moviliza en la competencia en un momento en el que hace falta más lógica colectiva. Por eso, si quiere tener legitimidad social en un momento como el actual, va a tener que incorporar aspectos que cuestionan la propia lógica productivista en la que se fundamenta. Para poder funcionar, requiere poderse justificar en términos de bien común. Elaborando modelos de justicia donde se garantice seguridad a las personas que participan en la comunidad. Boltanski y Chiapello (2002) apuntan a que, aunque parezca una paradoja, son estos elementos críticos con el funcionamiento del sistema los que hacen posible un camino para su legitimación social.

La empleabilidad entendida desde la lógica del bien común puede aportar alternativas a algunas de las críticas mencionadas. Son especialmente significativas las propuestas que abren la posibilidad de tener una relación diferente con el propio lugar de desempleado y aquellas que animan a inventar nuevas formas individuales y colectivas de inserción social y laboral en el marco de las economías transformadoras. Acciones que hacen posible construir nuevas lecturas compartidas sobre la propia situación recuperando la orientación al otro y el sentido de pertenencia y de utilidad social.

En este sentido, es importante poder señalar un punto fundamental en relación a la empleabilidad: se puede orientar desde una lógica neoliberal o desde una lógica del bien común. Desde la perspectiva neoliberal pone el foco exclusivamente en la consecución de un empleo pero la empleabilidad desde la perspectiva del bien común se abre a un planteamiento donde se la entiende como un proceso de provisión de bienes públicos a través de la cooperación y la participación. Un proceso que permite la producción de nuevas lógicas de encaje social (ECAS, 2019). Se trata de acciones de naturaleza colectiva que refuerzan la dimensión comunitaria en la medida que promueven procesos de construcción conjunta. Aquí, el acceso a los bienes públicos entendidos en clave de conocimientos, aptitudes, competencias, participación, etc., serían la piedra angular para la mejora de la empleabilidad. Pero no se trata de un conocimiento que genera competencia, sino obligaciones y responsabilidades colectivas. La empleabilidad desde la dimensión comunitaria se propone construir nuevas relaciones con la propia situación a partir de la adquisición de nuevos conocimientos compartidos que permiten inventar nuevas posibilidades para el vínculo social. De ello da cuenta el Informe de ECAS (2019) en el que el análisis de la experiencia de diferentes entidades que trabajan la empleabilidad con colectivos en dificultad permite entender cómo es posible situar en un lugar diferente al sujeto a través de un abordaje de la empleabilidad desde otra lógica. La emergencia con fuerza de nuevas modalidades de economías transformadoras abre nuevas vías para articular estas cuestiones a través de trabajos socialmente útiles. 
Vamos a situar cuatro ejes que nos pueden permitir entender la lógica de una empleabilidad no alineada con el marco neoliberal, tal y como se apunta en el análisis del trabajo realizado en el Programa Omnia (Orteu, 2016): por un lado la necesidad de saber leer la propia historia; en segundo, el tomar consciencia de la necesidad de la existencia de espacios para la construcción comunitaria; en tercer lugar, dar valor a la posibilidad de generar proyectos; y finalmente, algunas cuestiones en relación a los contenidos que articulan los proyectos personales:

- Saber leer la propia historia. Como hemos ido viendo, en la dinámica actual del mercado de trabajo, la propia trayectoria pasada ya no se percibe como una apuesta de futuro. No indica hacia dónde podemos o tenemos que ir. La acumulación lineal de experiencia desaparece como guía orientadora. Al mismo tiempo, las unidades de medida que permitían calibrar la valía profesional, borran sus sistemas fijos y se transforman en una serie de indicadores variables no siempre fáciles de usar para las personas.

Para Longo (2005) la inserción social y laboral actual supone que las personas deben disponer de un discurso sobre ellos mismos, sobre sus competencias y capacidades, sobre su proyecto, sobre su propia historia, sobre sus expectativas futuras, etc. En definitiva, deben poder articular en su propio discurso diferentes elementos que no necesariamente tienen una conexión clara. Este hecho, la construcción de este discurso sobre uno mismo, se convierte en un elemento decisivo para poder representarse socialmente $y$, por tanto, para poder encontrar espacios de reconocimiento.

En relación a esta cuestión, Claude Dubar (2001) planteaba la idea de que este discurso sobre uno mismo en realidad supone un doble trabajo. Un trabajo a nivel reflexivo y un trabajo a nivel narrativo. La reflexibilidad supone que la persona debe poder apropiarse de su experiencia. Por otra parte, la persona, debe ser capaz de hacer una narración. Articular estas capacidades en una trama que oriente el relato de uno mismo. Relato con lo que uno se puede presentar ante los demás. Esta reflexibilidad y narratividad cambia la manera clásica de ordenar las experiencias y los conocimientos laborales y permite su adaptación a nuevas formas de representación social.

- Espacios sociales para la construcción comunitaria. Como hemos ido viendo, antes se daban unos mecanismos claros para poder acceder al mercado laboral. Las referencias colectivas funcionaban y servían para todos. Incluso para aquellos que no querían incorporarse al mercado de trabajo. Sin embargo, actualmente se da un malestar identitario. Podemos decir que ha cambiado la relación entre lo individual y lo colectivo. El resultado es que cada vez es más difícil apoyarse en las acciones colectivas para buscar soluciones a las propias dificultades. El aislamiento es 
una de su expresión más visible. Pero esta individualidad que surge no es una individualidad que haga referencia a un exceso de intereses subjetivos. Se trata de una individualidad marcada por la falta de marcos colectivos. En esta situación, la individualidad se convierte en una amenaza para la propia persona. Longo (2005) plantea que si las personas no pueden compartir un pasado y un futuro, es difícil que dispongan de una dimensión comunitaria, de un proyecto colectivo. Hacen falta espacios, actividades y oportunidades en los que las personas puedan compartir estos relatos individuales. Es decir, el pasado, el presente y el futuro se articula a través de relatos compartidos y participados.

- Plantear un proyecto de futuro. Anteriormente, las diferentes instituciones organizaban los comportamientos sociales. Actualmente, estas canalizaciones se diluyen. Cada uno deviene responsable de lo que hace y se ve obligado a encontrar y dar un sentido a su vida. Las personas deben hacerse cargo de ellas mismas. En el nuevo marco social organizado en red, en nódulos que se conectan entre sí, la metáfora adecuada para dar cuenta de uno mismo es, como afirman Boltanski y Chiapello (2002), el proyecto. Este concepto permite dar sentido a las acciones, a las experiencias, no únicamente desde la lógica de tarea y función, sino que permite organizarla multiplicando los sentidos y las conexiones posibles. Es decir, permite una mayor imbricación en la comunidad y en las redes que la conforman. La idea de proyecto permite una mejor adaptación para el intercambio social en un momento en que trabajo y vida se confunden. La competencia de la fuerza de trabajo muta y se termina confundiendo con la personalidad (Riesco, 2001). Si las diferentes dimensiones personales se convierten potencialmente en empleabilidad, habrá que pensar nuevos instrumentos que nos permitan pensar nuevamente en el valor del trabajo tanto individual como colectivamente y a inventar nuevas formas para ubicarnos en él. Las personas pueden disponer de diferentes proyectos, laborales o no, que multiplican las posibilidades de conexión entre ellos y con la comunidad. Y esto puede evolucionar, ir cambiando en función de la interacción que se genere.

- Los contenidos que articulan los proyectos personales. Este aspecto tiene que ver con cuáles son los temas que articulan los proyectos. Hay que tener en cuenta que generar estos espacios de identificación comunitaria no es posible en abstracto. Siempre se hace en relación a un determinado problema, espacio de relaciones o situación. Ahora bien, es habitual que el punto de partida sea lo que Dubar (2001) denomina «individualismo negativo", lo que significa el cierre en identificaciones marcadas por la falta. En este caso, por la falta de trabajo. Esta propuesta limita las posibilidades de las personas y las deja en espacios de segregación. Por este motivo es importante que los contenidos de los proyectos tengan cuidado de este aspecto e incluyan nuevos posibles lugares a ocupar no marcados 
por el «no-trabajo». No marcados únicamente por la pérdida o la carencia. Esto será lo que permita nuevas oportunidades personales y colectivas. No significa no buscar empleo, sino que implica que se busca desde una propuesta más abierta que permite reconfiguraciones de la propia relación con el trabajo.

\section{Consideraciones finales}

Como hemos visto, el enfoque sobre la empleabilidad que predomina actualmente tiene una orientación claramente neoliberal, que se fundamenta en una doble convicción: por un lado, que el empleo es un bien escaso y que para acceder y mantenerlo se requiere de una aptitud de adaptación y aprendizaje constante para poder enfrentar los cambios actuales y futuros en los contenidos y en las modalidades de trabajar. Y por otro lado, que son las personas que quieren trabajar quienes tienen encomendada la tarea de «hacerse empleables» y ésta funciona como un mandato o precepto, es decir, con un marcado carácter normativo. Si bien esta orientación de la empleabilidad puede ser crítica por su deriva individualista, competitiva y mercantil como hemos visto, y su sobrevalorización puede resultar negativa, es precisamente en la reflexión sobre sus consecuencias donde podemos encontrar las líneas de trabajo que pueden encauzar la intervención con otro enfoque sobre la empleabilidad.

Es cierto que la situación excepcional que estamos viviendo en el momento en que redactamos estas líneas finales, en pleno "estado de alarma» decretado por la pandemia global del COVID-19, requiere de decisiones excepcionales y propuestas alternativas. En este sentido, en el ámbito laboral primero están llegando las medidas urgentes extraordinarias para hacer frente al impacto económico y social del COVID-19, como las recogidas en el Real DecretoLey 8/2020, de 17 de marzo, y en Real Decreto-Ley 9/2020, de 27 de marzo. Progresivamente avance la crisis serán necesarias más, pero posteriormente lo que es previsible es que el escenario económico, laboral y social que se presente abrirá las puertas a nuevos retos para a las políticas públicas y para las políticas de empleo en concreto. De momento, el principal reto va a ser combinar la protección de las personas trabajadoras, y sobre todo de los colectivos más vulnerables en el mercado de trabajo (personas desempleadas, temporales, empleadas del hogar, trabajadores y trabajadoras por cuenta propia, etc.) con una orientación necesariamente diferente de las políticas activas de empleo. En este sentido, dos líneas de trabajo resultan prioritarias:

Por un lado, nos encontramos con la necesidad de intervención sobre la creación de empleo, pero sobre la creación de un empleo que sea de calidad, dotado de garantías y de derechos laborales. Para conseguir los objetivos de la em- 
pleabilidad no debería valer cualquier empleo. También, sería necesario además intervenir y limitar las desigualdades en el mercado laboral, para que la empleabilidad pueda traducirse en un instrumento de capacitación y para que las personas tengan mayor poder y protagonismo en el diseño de sus vidas y de sus proyectos laborales. Si la inserción laboral es a través del empleo precario la empleabilidad debería carecer de sentido y utilidad.

Pero por otro, la atención a la dimensión colectiva y relacional del trabajo será clave en cualquier replanteamiento hacia otro enfoque de la empleabilidad. La desestabilización de los mecanismos tradicionales de acceso al trabajo genera grandes dosis de inseguridad imposibles de sostener sin espacios colectivos y comunitarios de construcción de estas nuevas narrativas. Hace falta poder contemplar las dinámicas generadas alrededor de las experiencias de las economías transformadoras como invenciones de nuevas actividades y nuevos lugares sociales desde donde participar (economías comunitarias, consumo responsable, economías feministas, economía social y solidaria, economía de los cuidados, etc.). De modo que el verdadero trabajo de la empleabilidad no consiste, o al menos no únicamente, en tratar de integrar en el mercado laboral a las personas excluidas y en potenciar las capacidades para mantener un empleo de las personas en situaciones de vulnerabilidad, sino en luchar por una transformación y consolidación de mejores condiciones de trabajo y de vida que eviten esos espacios de vulnerabilidad y exclusión. Donde la participación laboral de las personas ocupa un lugar central, porque se orientan hacia el bienestar y la protección de las personas trabajadoras. Y es que algunas de las herramientas más potentes que proporcionan estas experiencias transformadoras consisten en situar a las personas en el centro de los modelos productivos, redistribuir de forma equitativa los beneficios, económicos y de otro tipo, proporcionar actividades laborales de utilidad social o tomar los cuidados como una responsabilidad central y compartida (Pérez-Orozco, 2016). A partir de la confluencia de estas experiencias se podrán ir definiendo las políticas de transición hacia un futuro donde el crecimiento económico sea menos desigual, y por lo tanto más justo, ético y sostenible social y medioambientalmente.

Quizás el próximo escenario en el que tengamos que incorporar estos cambios en el modelo de empleabilidad sea la crisis económica y de empleo que se augura después de la crisis sanitaria provocada por la pandemia del COVID-19. Una cosa está clara: o somos capaces de incorporar la condición social como un elemento consustancial al hecho de trabajar, dando lugar y reconocimiento a sus diferentes expresiones o la receta neoliberal de priorizar los beneficios económicos arrastrará con lo que queda de una sociedad que tenía como objetivo el bienestar social basado en los futuros compartidos. 


\section{Bibliografía}

Alaluf, Mateo (2003), «La sociología del trabajo a través de una relectura de Claude Durand: situación de trabajo, cualificaciones, competencias y clase obrera», en Revista de Relaciones Laborales n. ${ }^{\circ}$ 2, pp. 93-102.

Alonso, Luis Enrique (2007), La crisis de la ciudadanía laboral. Barcelona: Antrophos.

AutÈs, M. (2004), «Tres formas de desligadura» en Karzs, S. (ed.), Exclusión: bordeando sus fronteras. Barcelona: Gedisa.

BArbier, Jean-Claude (2006), Analyse comparative de l'activation de la protection sociale en France, Grande Bretagne, Allemagne et Danemark, dans le cadre des lignes directrices de la stratégie européenne pour l'emploi. Paris: Centre d'Etudes de l'Emploi.

BARBIER, Jean-Claude (2001), Welfare to work policies in Europe: The current challenges of activation policies. Paris: Centre d'études de l'emploi.

Boden, Rebaca y Nedeva, Maria (2010), Employing discourse: Universities and graduate 'employability'. Journal of Education Policy, 25(1), 37-54. https://doi. org/10.1080/02680930903349489

Boltanski, Luke y Chiapello, Eve (2002), El nuevo espiritu del capitalismo. Buenos Aires: Akal.

Brown, Phillip; Hesketh, Anthony y Wiliams, Sara (2003), «Employability in a Knowledge-Driven Economy». Journal of Education and Work 16(2):107-26.

Brown, Phillip; Lauder, Hugh y Ashton, David (2011), The Global Auction: The Broken Promises of Education, Jobs and Incomes. Oxford University Press.

Castel, Robert (2006), La inseguridad social: ¿Qué es estar protegido? Buenos Aires: El Manantial.

Castells, Manuel (1996), La era de la información. Vol.1 La sociedad red Madrid: Alianza.

Carrasco, Cristina; Borderías, Cristina y Torns, Teresa (2011), El trabajo de los cuidados. Historia, Teoría y Politicas. Madrid: Catarata. Disponible en: https://www.fuhem. es/media/cdv/file/biblioteca/Economia_critica/El-trabajo-de-cuidados_introduccion. pdf

Chertkovskaya, Ekaterina; Watt, Peter; Tramer, Stefan; Spoelstra, Sverre (2013), "Giving notice to employability» Ephemera: Theory and Politics in Organization. Vol. 13, No. 4. pp. 701-716.

Crespo, Eduardo; Prieto, Carlos y Serrano, Amparo (coords.) (2009), Trabajo, subjetividad y ciudadanía. Paradojas del empleo en una sociedad en transformación. Madrid: Editorial Complutense.

De la Cal, Ma Luz y De la Fuente, Mikel (2011), Algunos interrogantes en torno a los programas de inclusión activa como estrategia de lucha contra la pobreza y la exclusión social. Lan Harremanak-Revista de Relaciones Laborales (22). Disponible en: https://www.ehu.eus/ojs/index.php/Lan_Harremanak/article/view/1388

De la Garza Toledo, Enrique (2009), «Hacia un concepto ampliado de trabajo» en Nefa, J.C.; De la Garza, E y Muñiz, L. (coord.), Trabajo, empleo, calificaciones profesionales, relaciones de trabajo e identidades laborales. Buenos Aires: Clacso.

Dubar, Claude (2001), "El trabajo y las identidades profesionales y personales» en Revista Latinoamericana de Estudios del Trabajo. Año 7, núm. 13.

ECAS (2019), «Entre l'ocupació i el treball. Davant la manca d'ocupació, restituïm el valor social del treball» en https://acciosocial.org/wp-content/uploads/2019/07/Entreocupacio-i-treball_informe-ECAS1.pdf 
Eurofound; International Labour Office (2019), Working conditions in a global perspective. Publications Office of the European Union; Geneva, International Labour Office. Disponible en: https://www.eurofound.europa.eu/sites/default/files/ef_ publication/field_ef_document/ef18066en.pdf

FOESSA (2019), VIII Informe sobre exclusión y desarrollo social en España, Madrid: Fundación FOESSA y Cáritas.

Foucault, Michel (2007), Nacimiento de la biopolitica: curso en el Collège de France (1978-1979). México: Fondo de Cultura Económica.

Gazier, Bernard (2001), "Employability - The complexity of a policy notion», en P. Weinert, M. Baukens, P. Bollerot, M. Pineschi-Gapenne and U. Walwei (eds.), Employability: From theory to practice. Somerset, NJ: Transaction Publishers.

García Calavia, Miguel Angel (2013), «Trabajar sin los otros o en qué se ha convertido el trabajo asalariado hoy» en Linhart, D.: Trabajar sin los otros.Valencia: PUV.

Guilbert, Laure; Bernaud, Jean-Luc; Gouvernet, Brice y Rossier, Jérôme (2016), «Employability: Review and research prospects». International Journal for Educational and Vocational Guidance, 16(1), 69-89. https://doi.org/10.1007/s10775-0159288-4

Laparra, Miguel y Pérez-Eransus, Begoña (2008), Exclusión Social en España. Un espacio diverso y disperso en intensa transformación. Madrid: Fundación Foessa. Cáritas.

Laval, Christian, y Dardot, Pierre (2013), La nueva razón del mundo. Ensayo sobre la sociedad neoliberal. Barcelona: Gedisa

Lefresne, Florence (1999), "Employability in the heart of the European Employment Strategy». European Review of Labour and Research 5: 460-480. https://doi. org/10.1177/102425899900500404

LinharT, Danielle (2013), Trabajar sin los otros. Valencia: PUV.

Longo, M. a Eugenia (2005), «Un tiempo. La socialización en el trabajo en un contexto de transformaciones» en Nuevos escenarios en el mundo del trabajo: rupturas y continuidades». Buenos Aires: VII Congreso Nacional de Estudios del Trabajo.

Manzanera-Román, S., Ortíz García, P. y Hernández Pedreño, M. (2016), Crisis del factor trabajo como vía de integración social. Cuadernos De Relaciones Laborales, 34(1), 15-35. https://doi.org/10.5209/rev_CRLA.2016.v34.n1.52004

McQuaid, R.W. and C. Lindsay (2005), The Concept of Employability. Urban Studies 42 (2): 197-219. Doi:10.1080/0042098042000316100

MÉda, Dominique (2019), "Tres escenarios para el futuro del trabajo», Revista Internacional del Trabajo, vol. 138, n. ${ }^{\circ}$ 4, pp. 676-702.

Moruno, Jorge (2015), La fábrica del emprendedor. Trabajo y política en la empresamundo, Madrid: Akal.

Moulier-Boutang, Yann; Corsani, Antonella y Lazzarato, Maurizio (2004), Capitalismo cognitivo, propiedad intelectual y creación colectiva, Madrid: Traficantes de sueños.

Muñoz, David y Santos, Antonio (2017), «Las "cárceles del capital humano": trabajo y vidas precarias en la juventud universitaria", en RECERCA. Revista de Pensament y Anàlisi, N. 20, 59-78. https://doi.org/10.6035/Recerca.2017.20.4

Organización Internacional del Trabajo (OIT) (2020), Observatorio de la OIT: El COVID-19 y el mundo del trabajo. Segunda edición. Estimaciones actualizadas y análisis. 7 de abril de 2020. Disponible en: https://www.ilo.org/wcmsp5/groups/public/--dgreports/---dcomm/documents/briefingnote/wcms_740981.pdf

Orteu, Xavier (2012), Trabajo y vínculo social. Barcelona: Ed. UOC. 
Orteu, Xavier (coord.) (2016), Millora de l'ocupabilitat des de l'acció comunitària. Barcelona: Dep. Treball, Afers Socials i Famílies de la Genralitat de Catalunya. Colección Eines, núm. 28.

Peck, Jamie y Theodore, Nik (2000), "Beyond employability», Cambridge Journal of Economics, pp. 729-749. https://doi.org/10.1093/cje/24.6.729

Pérez Orozco, Amaia (2014), Subversión feminista de la economía: aportes para un debate sobre el conflicto capital-vida, Madrid: Traficantes de Sueños.

Rose, Nikolas (1999), Governing the soul. The shaping of the private self (2nd ed.). London: Free Association Books.

Riesco-Sanz, Alberto (2001), «Boltanski-Chiapello y la gran transformación», Cuadernos de Relaciones Laborales, núm. 18, Madrid.

Santamaría, Elsa, y Carbajo, Diego (2019), "Emergencias de la crisis: Figuras antiheroicas del emprendimiento juvenil en España», Política y Sociedad, 56(1), 191-211. https://doi.org/10.5209/poso.60030

Santos-Ortega, Antonio (2008), Las nuevas formas de representación del paro: Crítica de la idea de activación, empleabilidad y competencias. Empleo y exclusión social: rentas mínimas y otros mecanismos de inserción sociolaboral, págs. 131-144. https:// dialnet.unirioja.es/servlet/articulo?codigo $=6414643$

Schiller, Dan (2000), Digital Capitalism. Networking the Global Market System, MIT Press, Cambridge

Serrano, Amparo (2000), «El concepto de empleabilidad en la estrategia europea de lucha contra el desempleo: una perspectiva crítica», Revista del Ministerio de Trabajo y Asuntos Sociales 21.

Serrano, Amparo (2009), «Regulación supranacional y despolitización del trabajo: el caso del paradigma de la activación», en Crespo, E.; Prieto, C. y Serrano, A. (coords.), Trabajo, subjetividad y ciudadanía. Paradojas del empleo en una sociedad en transformación. Madrid: Centro de Investigaciones Sociológicas, pp. 259-289.

Serrano, Amparo y Martín, Paz (2017), From 'Employab-ility' to 'Entrepreneurial-ity' in Spain: youth in the spotlight in times of crisis, Journal of Youth Studies, 20:7, 798-821, https://doi.org/10.1080/13676261.2016.1273513

Standing, Guy (2013), El Precariado: una nueva clase social. Barcelona: Pasado y Presente.

Subirats, Joan.; Gomà, R.; Brugue, J. (coords.) (2005), Análisis de los factores de exclusión social. Riesgos de exclusión social en las Comunidades Autónomas. IGOP-UAB Documentos de Trabajo 5, Fundación BBVA, /Institutd'EstudisAutonòmics, 2005. Disponible en: https://www.fbbva.es/wp-content/uploads/2017/05/dat/DT_2005_04.pdf

Tomlinson, Michael y Holmes, Leonald (2017), Graduate Employability in Context. Theory, Research and Debate. Londres: Springer.

Yorke, Mantz (2006), Employability in higher education: What it is - What it is not (Vol. 1). York: The Higher Education Academy.

WaCQUANT, Loïc (2011), Castigar a los pobres. El gobierno neoliberal de la inseguridad social, Barcelona: Gedisa. 